\title{
Noonan syndrome: a case report
}

\author{
Muhammet E. Emral and Mehmet O. Akcam \\ Department of Orthodontics, Faculty of Dentistry, University of Ankara, Ankara, Turkey
}

(Received 17 September 2008 and accepted 9 February 2009)

\begin{abstract}
Cranio-dento-facial findings in a case of Noonan syndrome in a 13-year, 3-month-old male are reported. Oral examination of the patient revealed a narrow, high arched palate, malocclusion and congenitally missing teeth. Even though cephalometric measurements showed an increased vertical facial pattern $\left(\mathrm{GoGn} / \mathrm{SN}=38.46^{\circ}\right)$, a severe deep bite $(9 \mathrm{~mm})$ was evident. Noonan syndrome is characterized by ocular, facial, cardiac, and dental anomalies, although it is often unrecognized by clinicians. Although differential diagnosis of this syndrome is difficult, the cranio-dento-facial structures show specific findings that can be diagnosed by a dental specialist. The present report describes a new case of this syndrome from a dental viewpoint. (J Oral Sci 51, 301-306, 2009)
\end{abstract}

Keywords: Noonan syndrome; dental; orthodontic.

\section{Introduction}

Noonan syndrome was first described by Noonan and Ehmke in 1963 as a multisystem disorder (1). It is mainly characterized by clinical features such as short stature, hypertelorism, ptosis, and low-set ears $(1,2)$. In addition, congenital heart diseases, digestive problems, swallowing difficulties, cryptorchidism, lymphedema, mental retardation and poor coordination, learning disabilities, speech delays, joint or muscle pain, coagulation deficiencies, bluntly ended fingers and keloids have been reported (3-6). Noonan syndrome affects both males and females, and has an estimated incidence of between 1 per

Correspondence to Dr. Muhammet E. Emral, A.U. Dis Hekimligi Fakultesi, Ortodonti A.D, Ankara Universitesi, Ankara 06500, Turkey

Tel: +90-312-2965651

Fax: +90-312-2130960

E-mail: dtemrahemral@hotmail.com
1,000 and 1 per 2,500 live births, which appears to be consistent worldwide (7).

This condition is often likened to Turner syndrome, which is characterized by epicanthic folds, right-sided congenital heart disease, and various skeletal malformations (8), although the genetic causes are different. In Noonan syndrome, no consistent chromosomal anomaly has been found $(9,10)$. Jamieson et al. (3) localized the gene to chromosome $12(\mathrm{Zmax}=4.04$ at $0=0.0)$, at $12 \mathrm{q}$, between D12S84 and D12S366. To date, many cases have been reported, but there have been few descriptions of the cranio-dento-facial features. Therefore, the present report describes the cranio-dento-facial findings in a case of Noonan syndrome.

\section{Case Report}

The patient, a 13-year, 3-month-old male, presented with malalignment of his teeth in the upper and lower dental arches. A detailed medical and dental history was obtained from the patient and from his parents. The patient's father had the same syndrome.

Medical findings

There was a history of consanguineous marriage in the family. Physical examination revealed facial dismorphism, bilateral telecanthus, hypertelorism, visual defect (myopia, 13 diopter), a relatively short stature (height: $128 \mathrm{~cm}$, weight: $30 \mathrm{~kg}$ ), low neck-hair line, mane neck, a high palatal vault, asymmetry between the left and right thorax and pectus excavatum, and widely spaced nipples. No marked cardiac abnormality was observed and the patient had a normal electrocardiogram. However, his medical/ genetic consultant suggested a regular follow-up for monitoring of a suspected cardiac transmission defect. Similar findings were observed in the patient's father, including short stature, a low neck-hair line, widely spaced nipples and also a history of cardiac valve surgery. It is well known that Noonan syndrome is an autosomal 
dominant condition and may show clinical differences within the same family. Although not tested, the patient appeared to have normal intelligence.

\section{Facial features (Fig. 1)}

Hypertelorism, drooping eyelids (ptosis), a normal vertical facial pattern, an asymmetric smile, low-set ears, a thick helix of the ear (outer rim), a small upturned nose, a broad forehead, a deeply grooved philtrum and normal facial profile were observed. No sign of facial asymmetry was evident from a frontal photograph.

\section{Intra-oral examination (Fig. 2)}

Intraorally the patient showed a bilateral Angle Class II canine relationship with diastema in the maxillary dentition. He had severe crowding in the mandibular anterior region, where the lower left lateral incisor was lingually malposed. The lower right first molar had been extracted when the patient was 9 years old, and the lower left first molar showed mesiobuccal rotation. A severe deep bite was noted with a $9.00-\mathrm{mm}$ overbite. The lower second premolars, upper lateral incisors, and upper and

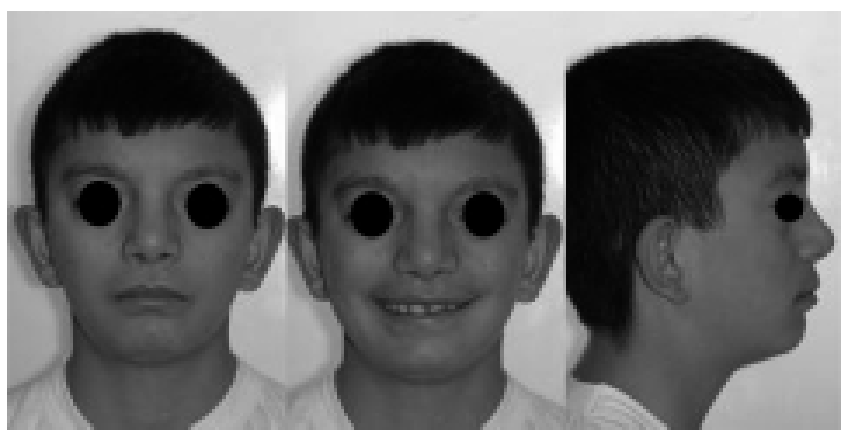

Fig. 1 Facial photographs of the proband. lower third molars were congenitally absent.

Oral examination revealed a high palatal vault and a significantly deep bite. Left-right asymmetry of tooth morphology was evident, particularly the upper first molars.

\section{Dental cast measurements}

Palatal height was measured using a digital caliper from the hard palate to the occlusal plane. An increasing palatal height was observed from the incisor to the molar region, i.e. palatal depth 1-1 (incisors): $2 \mathrm{~mm}, 3-3$ (canines): $3 \mathrm{~mm}$, 4-4 (first premolars): $10 \mathrm{~mm}, 6-6$ (first molars): $13 \mathrm{~mm}$.

\section{Radiographic examination (Fig. 3)}

A lateral cephalometric film revealed a craniofacial pattern that was within normal limits, with a harmonious profile and a normal upper airway. A panoramic film revealed that the upper right and left second premolars had atypical morphology and impaction. The lower right and left second molars were also impacted. No carious lesions were evident clinically or radiographically.

Hand-wrist radiography demonstrated a slightly retarded bone age (13 years old) according to the standards of Greulich and Pyle (11). When compared to chronological age (i.e. 13 years, 3 months), he was at developmental stage MP3 = (maturation stage of the medium phalanx of the third finger, which usually appears during the onset of the accelerating growth period), just before the peak pubertal growth period.

\section{Cephalometric findings}

A skeletal Angle Class I pattern $\left(\mathrm{ANB}=1.31^{\circ}\right)$ with lower incisor retrusion (lower incisor to NB-Nasion to $\mathrm{B}$ point-line; $-2.52 \mathrm{~mm}$ ) was observed. An increased vertical facial angle $\left(\mathrm{GoGn} / \mathrm{SN}=38.46^{\circ}\right)$ was observed, but severe deep bite was also present.

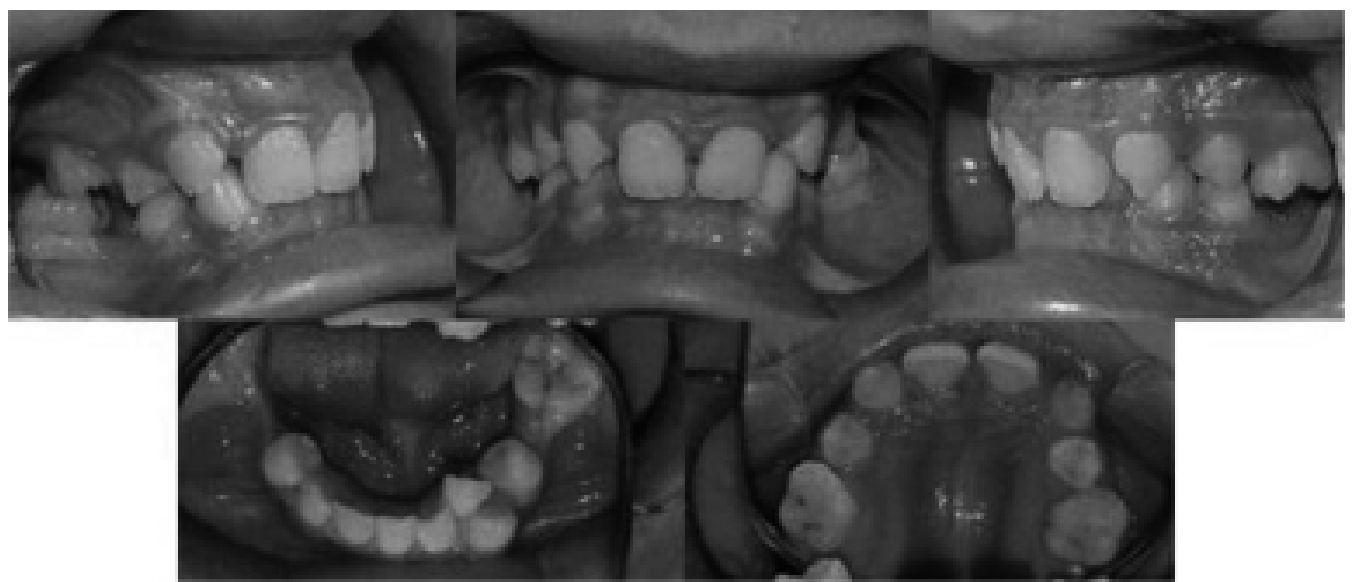

Fig. 2 Intraoral photographs of the proband. 


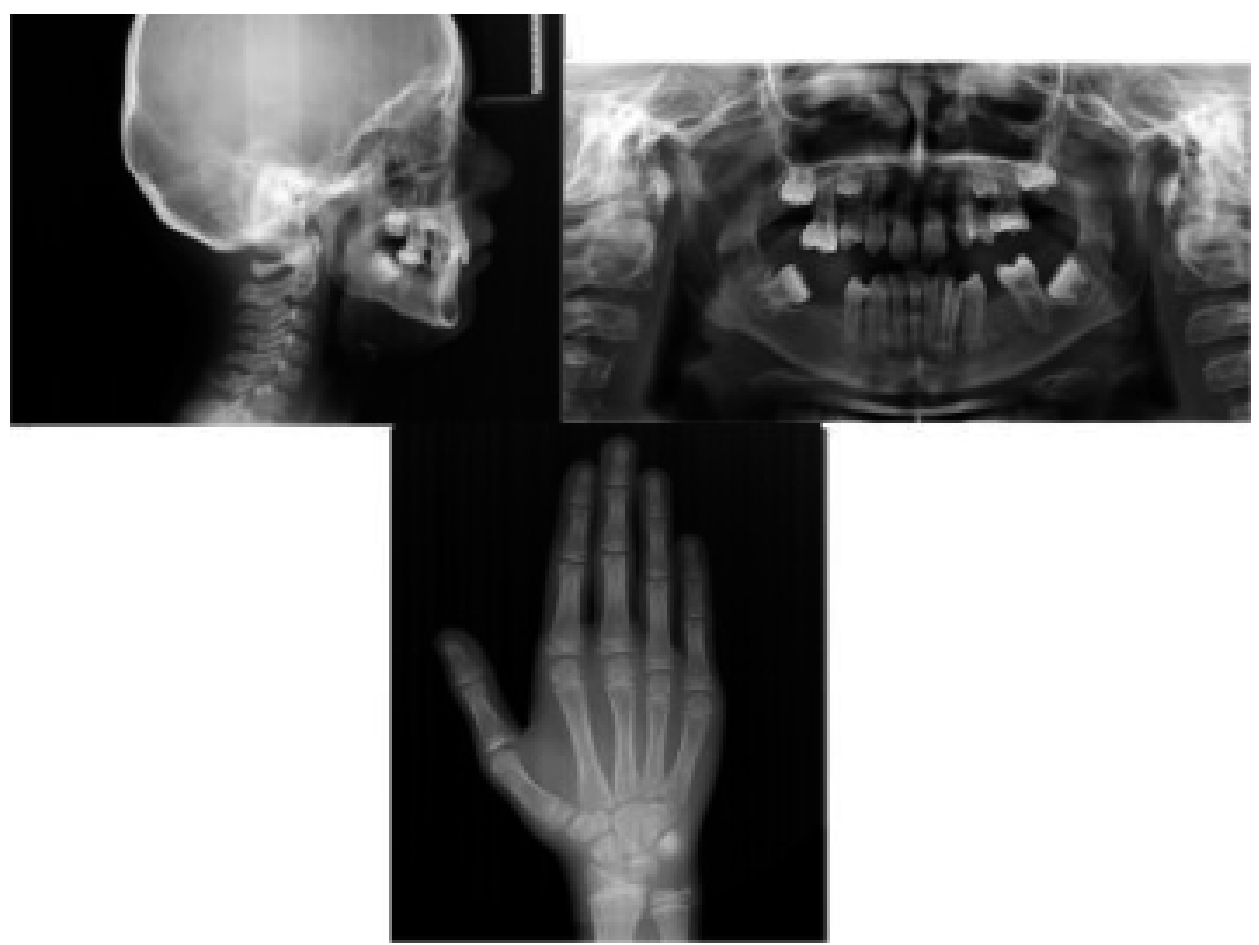

Fig. 3 Radiographic images of the proband.

The cephalometric landmarks are shown in Fig. 4, and Table 1 shows the patient's cephalometric measurements. The SNA (Sella-Nasion-A point angle) and SNB (SellaNasion-B point angle) angles were significantly smaller, and the occlusal plane/SN and GoGn/SN (GonionGnathion/Sella-Nasion angle) angles were much larger than normal. The Holdaway difference was $-4.18 \mathrm{~mm}$, indicative of mandibular incisor retrusion. The interincisal angle was significantly increased $\left(162.92^{\circ}\right)$.

\section{3-D CT (computed tomography) findings (Fig.} 5)

The upper second molars were impacted; the upper right second premolar was $7 \mathrm{~mm}$ below the alveoler crest tip and $1.5 \mathrm{~mm}$ from the buccal alveolar end. The upper left second premolar was impacted. In the lower dental arch, impacted second molars were observed on the right and left sides. The third molars were missing in the upper and lower dental arches.

\section{Treatment plan}

A multidisciplinary approach, i.e., orthodontic and prosthodontic treatment, was planned which was approved by the ethics committee of the institution.

\section{Discussion}

Noonan syndrome is a relatively common congenital

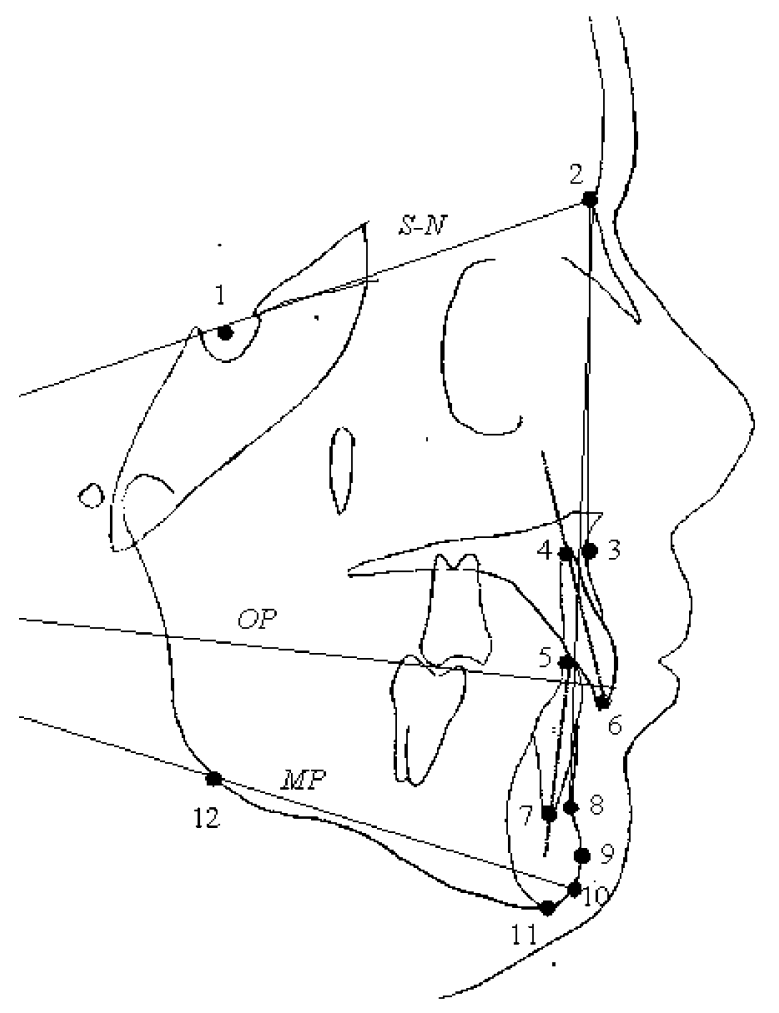

Fig. 4 Cephalometric drawing and landmarks; 1. Sella, 2. Nasion, 3. Point A, 4. Uia (upper incisor apex), 5. Lit (Lower incisor tip), 6. Uit (Upper incisor tip), 7. Lia (lower incisor apex), 8. Point B, 9. Pogonion, 10. Gnathion, 11. Menton, 12. Gonion; S-N: Sella Nasion Plane, OP: Occlusal Plane, MP: Mandibular Plane. 
Table 1 Cephalometric measurements

\begin{tabular}{lcc}
\hline Parameter & Norm (Mean \pm SD) & Case \\
\hline SNA (deg.) & $82 \pm 3.9$ & \\
SNB (deg.) & $80 \pm 3.6$ & 69.36 \\
ANB (deg.) & $2 \pm 1.8$ & 68.05 \\
Uit- NA (mm) & 4 & 1.31 \\
Uit-Uia/NA (deg.) & 22 & 2.19 \\
Lit- NB (mm) & 4 & 12.36 \\
Lit-Lia/NB (deg.) & 25 & -2.52 \\
Pg-NB (mm) & 0 & 3.42 \\
Holdaway difference (mm) & & 1.66 \\
(Lit.NB - Pg.NB) & 131 & -4.18 \\
Interincisal angle (deg.) & 32 & 162.92 \\
GoGn/SN (deg.) & 14 & 38.46 \\
Occlusal plane/SN (deg.) & & 27.86 \\
\hline
\end{tabular}

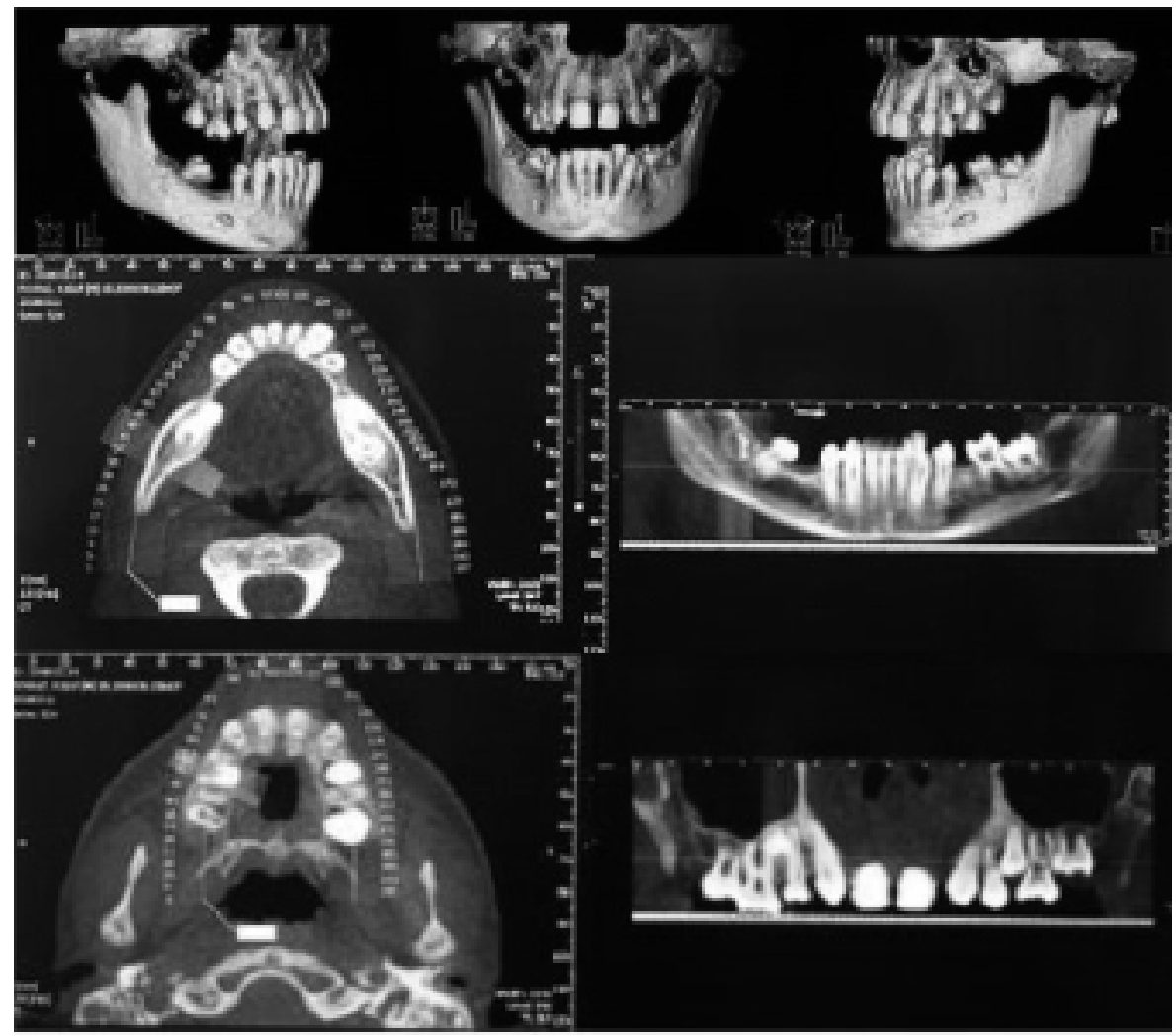

Fig. 5 3D CT images of the proband.

genetic anomaly and effects both males and females. It is an autosomal dominant anomaly, and any person affected has up to a $50 \%$ chance of transmitting it to their children $(9,12)$. The severity of the features may vary greatly in patients with Noonan syndrome and among family members. Even though the syndrome is not always identified early, therapy is more effective if an early diagnosis is possible. Since Noonan syndrome is one of the most common genetic conditions associated with congenital heart disease, i.e., almost $2 / 3$ of patients have a congenital heart defect (50\% have pulmonary valvular stenosis and $10 \%$ have septal defects) (3).

Nelson et al. reported that Noonan syndrome was characterized by a narrow high-arched palate (13). There 
have been several other reports describing the oral features of this syndrome (13-16), but few descriptions of a narrow high-arched palate with an open bite $(15,16)$. Sugar et al. (17) described a patient with Noonan syndrome who had marked mandibular prognathism with an anterior open bite. Although the present patient showed a severe deep bite with a hyperdivergent pattern, this could have been attributable to congenitally missing teeth.

The present patient showed a markedly higher palate at the measured points in the upper dentition, particularly in the posterior region, accompanied by a small maxillary dental arch. It has been reported that early closure of the cranial sutures may influence the growth of the dental arch (18). Kreiborg and Pruzansky (18) suggested that, in premature craniosynostosis, malocclusion is best explained by a lack of maxillary sutural growth in all three planes of space. The results of cephalometric measurements in the present case demonstrated an increased vertical facial angle (GoGn/SN) and in addition, the facial height (N-Me and ANS-Me) exceeded the normal range. Even though the cephalometric measurements indicated an open bite, deep-bite malocclusion was present. Therefore, the treatment plan involved initial placement of a functional appliance (deep bite activator), followed by fixed Edgewise mechanics, and finally, prosthodontic management.

On the basis of our experience, we consider that the following points should be borne in mind before orthodontic treatment in patients with Noonan syndrome:

- Since poor coordination, learning disabilities, speech and language delays or even mild mental retardation may be present (reported in 1/3 of patients), application of a removable or fixed appliance may be difficult, although patients are reported to respond well to speech therapy.

- Swallowing difficulties, frequent vomiting, digestive problems and decreased apetite may cause growth retardation.

- Temporomandibular joint or muscle pain with no identifiable cause may be present.

- The pubertal growth spurt might be reduced or delayed, and therefore a hand-wrist film can be useful for determination of growth stage. Administration of growth hormone can be considered if necessary.

- As bleeding anomalies, blood clotting disorders, epistaxis and combined coagulation deficiencies have been reported, a full hematologic workup must be performed before any planned operation, such as orthognathic surgery (19). Subjects with bleeding disorders should be warned against the use of aspirin or other medications that interfere with coagulation.

- Low set, backward-rotated ears and a thick ear helix have been reported as key diagnostic features in over $90 \%$ of cases. It should be kept in mind that chronic otitis media may also be present.

- A deeply grooved philtrum has been reported in over $90 \%$ of cases. Poor tongue control may present difficulties when treating open bite.

- Even though the genes associated with Noonan syndrome have been identified, diagnosis is based mainly on clinical features (16). Characteristic dental and skeletal structures can be diagnosed by a dental professional, and therefore dentists can play a major role in the differential diagnosis of this syndrome.

\section{References}

1. Noonan JA, Ehmke DA (1963) Associated noncardiac malformation in children with congenital heart disease. J Pediatr 63, 468-470.

2. Tuner HH (1938) A syndrome of infantilism, congenital webbed neck and cubitus valgus. Endocrinology 23, 566-574.

3. Jamieson CR, van der Burgt I, Brady AF, van Reen M, Elsawi MM, Hol F, Jeffery S, Patton MA, Mariman E (1994) Mapping a gene for Noonan syndrome to the long arm of chromosome 12. Nat Genet 8, 357-360.

4. Noonan JA (1999) Noonan syndrome revisited. J Pediatr 135,667-668.

5. Qiu WW, Yin SS, Stucker FJ (1998) Audiologic manifestations of Noonan syndrome. Otolaryngol Head Neck Surg 118, 319-323.

6. Sharland M, Burch M, McKenna WM, Paton MA (1992) A clinical study of Noonan syndrome. Arch Dis Child 67, 178-183.

7. Nora JJ, Nora AH, Sinha AK, Spangler RD, Lubs HA (1974) The Ullrich-Noonan syndrome (Turner phenotype). Am J Dis Child 127, 48-55.

8. Noonan JA (1968) Hypertelorism with Turner phenotype. A new syndrome with associated congenital heart disease. Am J Dis Child 116, 373380.

9. Sharland M, Morgan M, Smith G (1993) Genetic counseling in Noonan syndrome. Am J Med Genet 45, 437-440.

10. Allanson JE (1987) Noonan syndrome. J Med Genet 24, 9-13.

11. Greulich WW, Pyle SI (1959) Radiographic atlas of skeletal development of the hand and wrist. 2nd ed, Stanford University Press, Stanford, 1-256.

12. Tartaglia M, Kalidas K, Shaw A, Song X, Musat DL, van der Burgt I, Brunner HG, Bertola DR, Crosby A, Ion A, Kucherlapati RS, Jeffery S, Patton MA, 
Gelb BD (2002) PTPN11 mutations in Noonan syndrome: molecular spectrum, genotype-phenotype correlation, and phenotypic heterogeneity. Am J Hum Genet 70, 1555-1563.

13. Nelson JF, Tsaknis PJ, Konzelman JL (1978) Noonan's syndrome: report of a case with oral findings. J Oral Med 33, 94-96.

14. Bernier-Buzzanga J, Su WP (1990) Noonan's syndrome with extensive verrucae. Cutis $46,242-$ 246.

15. Horowitz SL, Morishima A (1974) Palatal abnormalities in the syndrome of gonadal dysgenesis and its variants and in Noonan's syndrome. Oral Surg Oral Med Oral Pathol 38, 839-844.
16. Okada M, Sasaki N, Kaihara Y, Okada R, Amano H, Miura K, Kozai K (2003) Oral findings in Noonan syndrome: report of a case. J Oral Sci 45, 117-121.

17. Sugar AW, Ezsias A, Bloom AL, Morcos WE (1994) Orthognathic surgery in a patient with Noonan's syndrome. J Oral Maxillofac Surg 52, 421-425.

18. Kreiborg S, Pruzansky S (1981) Craniofacial growth in premature craniofacial synostosis. Scand J Plast Reconstr Surg 15, 171-186.

19. Singer ST, Hurst D, Addiego JE Jr (1997) Bleeding disorders in Noonan syndrome: three case reports and review of the literature. J Pediatr Hematol Oncol 19, 130-134. 